\title{
Fatores edáficos determinando a ocorrência de leguminosas herbáceas em savanas amazônicas
}

\author{
Claymir de Oliveira CAVALCANTE ${ }^{1}$, Andréia Silva FLORES ${ }^{2}$, Reinaldo Imbrozio BARBOSA ${ }^{3 *}$ \\ 1 Universidade Federal de Roraima - UFRR. Programa de Pós-graduação em Recursos Naturais - PRONAT, Campus Paricarana, 69304-000. Boa Vista-Roraima-Brasil. \\ E-mail: consult.claymir@gmail.com \\ 2 Instituto de Amparo a Ciência, Tecnologia e Inovação do Estado de Roraima - IACTI/RR. Museu Integrado de Roraima - MIRR, Parque Anauá, 69305-010. \\ Boa Vista-Roraima-Brasil. E-mail: andreiasflores@gmail.com \\ 3 Instituto Nacional de Pesquisas da Amazônia - INPA. Coordenação de Dinâmica Ambiental - CDAM, Núcleo de Pesquisas de Roraima - NPRR, Rua Coronel Pinto 315 - Centro, \\ 69301-150. Boa Vista-Roraima-Brasil. \\ * Autor correspodente: reinaldo@inpa.gov.br
}

\section{RESUMO}

Fatores edáficos vem sendo indicados como determinantes para a distribuição de comunidades de plantas na Amazônia. O objetivo deste estudo foi investigar quais fatores edáficos determinam a ocorrência de leguminosas herbáceas em savanas amazônicas. Para tanto, foi realizado um inventário da flora herbácea da família Leguminosae em 34 parcelas permanentes estabelecidas em duas áreas de savana de Roraima, norte da Amazônia brasileira. As espécies Chamaecrista desvauxii (24,9\%), Aeschynomene histrix (15,7\%) e Galactia jussiaeana (10,8\%) foram as de maior índice de valor de importância. Todas com grande abundância e ampla distribuição. Os resultados indicaram baixa densidade ou ausência de indivíduos e espécies em parcelas estabelecidas em solos mal drenados (hidromórficos). Diversidade e riqueza de espécies tendeu a ser maior em habitats formados por solos bem drenados, mais férteis e com menor concentração de alumínio trocável. É sugerido que solos pobres e sazonalmente alagados reduzam as chances de ocorrência e afetem negativamente a riqueza/diversidade de leguminosas herbáceas nas áreas de savana de Roraima.

PALAVRAS-CHAVE: ecologia de comunidades, cerrado, lavrado, Roraima

\section{Edaphic factors determining the occurrence of herbaceous legumes in Amazonian savannas}

\section{ABSTRACT}

Edaphic factors have been indicated as a determinant of the distribution of plant communities in Amazonia. The aim of this study was to detect which edaphic factors determine the occurrence of herbaceous legumes in Amazonian savannas. Therefore, an inventory of herbaceous flora of the family Leguminosae was conducted in 34 permanent plots established in two savanna areas of Roraima, northern Brazilian Amazon. The importance value index was higher for Chamaecrista desvauxii (24.9\%), Aeschynomene hystrix (15.7\%) and Galactia jussiaeana (10.8\%), all having high abundance and wide distribution. The results indicated low density or absence of individuals and species in plots established on poorly drained soils (hydromorphic). Diversity and species richness tended to be higher in habitats formed on well drained soils, greater fertility and lower concentrations of exchangeable aluminum. It is suggested that poor and seasonally flooded soils tend to reduce the chances of occurrence of herbaceous legumes in savanna areas of Roraima, adversely affecting its richness/diversity.

KEYWORDS: ecology of community, cerrado, lavrado, Roraima 
Campos e savanas ocupam ca. $200.000 \mathrm{~km}^{2}(-5 \%)$ do bioma Amazônia e estáo dispersos de forma isolada (encraves) e não isolada (periférica) ao longo do contínuo florestal sob diferentes tipos climáticos, fatores edáficos, relevo e distúrbios antropogênicos (Sanaiotti et al. 2002; Santos et al. 2007). Essa dispersão geográfica determina padróes de diversidade florística e estrutural distintos nas escalas local e regional (Ratter et al. 2003). Contudo, os padrôes de distribuição de comunidades de plantas destes ambientes ainda são pobremente conhecidos. Os poucos estudos existentes desenvolveram suas investigaçóes principalmente com comunidades arbóreo-arbustivas abordando florística e estrutura (Barbosa et al. 2005; Miranda et al. 2006) ou distribuiçấo espacial em funçấo de fatores ambientais (Miranda et al. 2002). Pouca atenção tem sido dada às comunidades de plantas herbáceas, embora seja reconhecido que este componente apresente grande diversidade em campos e savanas da Amazônia (Miranda e Absy 2000; Magnusson et al. 2008).

Da mesma forma como em ambientes florestais amazônicos (Tuomisto et al. 2003; Costa 2006), a hipótese geral é que plantas herbáceas de savanas também possuam ocorrência determinada por fatores edáficos condicionados pela heterogeneidade ambiental. Esta, por sua vez, pode ser distinta por diferentes classes de solo, relevo ou mesmo padróes de drenagem. Para entender como grupos específicos de plantas ocorrem em áreas de savana da Amazônia em funçáo de fatores edáficos, foi realizado um inventário das plantas herbáceas terrestres da família Leguminosae (sensu Lewis et al. 2005) em duas áreas de savana situadas no nordeste do estado de Roraima. Esta ecorregiáo é localmente conhecida por lavrado e se constitui na maior área contínua de savana da Amazônia brasileira $\left(-43.000 \mathrm{~km}^{2}\right)$ (Barbosa e Campos 2011). Leguminosae foi utilizada como grupo modelo neste trabalho porque é uma das mais ricas famílias de ervas terrestres da savana de Roraima (Miranda e Absy 2000). Os objetivos específicos deste estudo foram determinar (i) a riqueza e a diversidade das espécies deste grupo e (ii) os padrôes de ocorrência em função de habitats determinados por variáveis edáficas.

O estudo foi conduzido em 34 parcelas permanentes estabelecidas em duas áreas (grades) do Programa de Pesquisa em Biodiversidade (PPBio) situadas na savana de Roraima: Campo Experimental Água Boa - Embrapa Roraima (22 parcelas; 02० 39' 31" N / 60० 51' 11" W) e Campus do Cauamé (Monte Cristo) - Universidade Federal de Roraima (12 parcelas; 02。 52' 29” N / 60 42' 56" W) (Figura 1). Ambas as áreas são de baixa altitude (70-80 m), clima Aw pela classificação de Köppen e precipitação média anual $c a$.

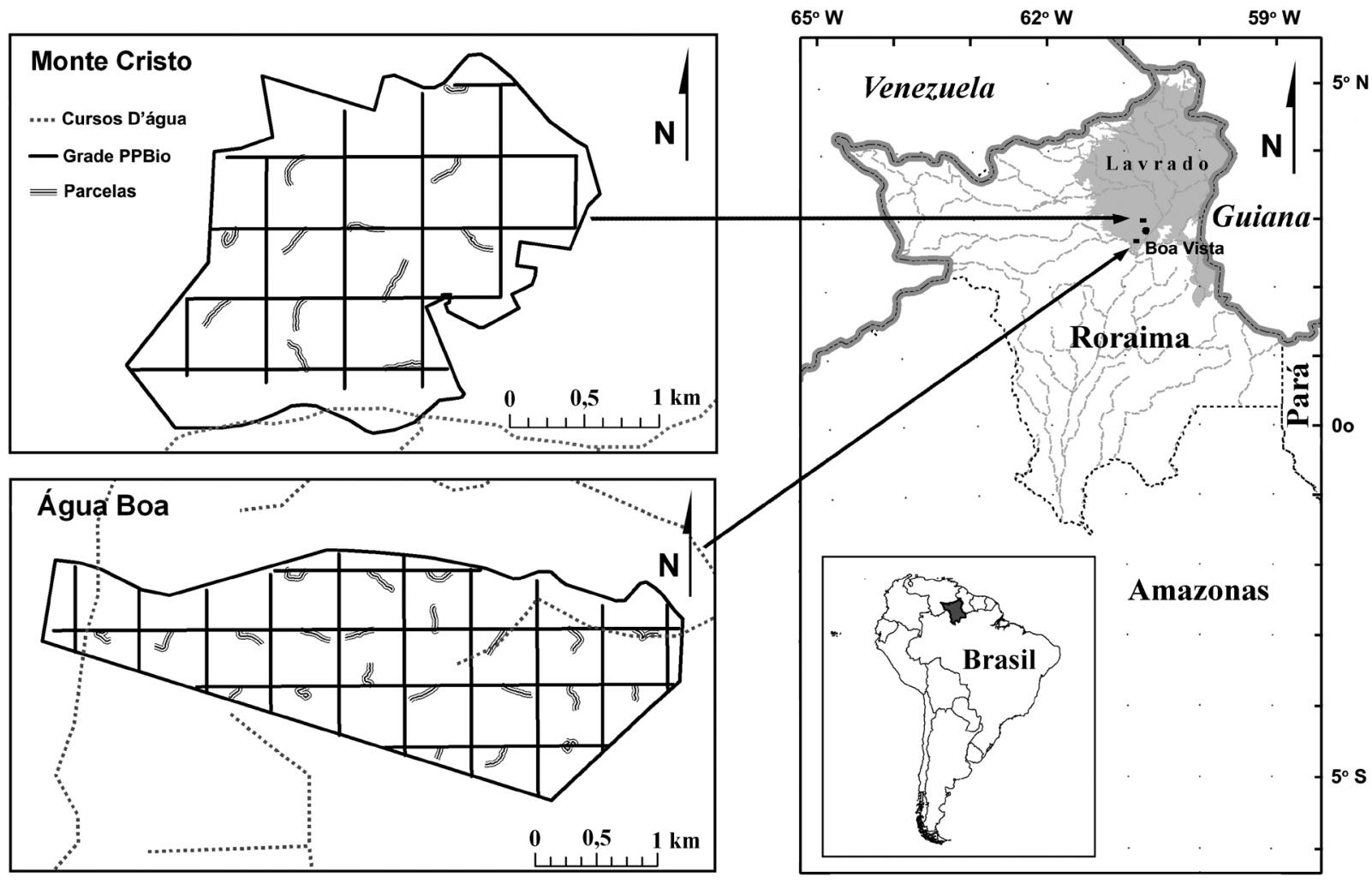

Figura 1 - Localização das áreas de estudo e distribuição das parcelas amostrais no Lavrado (Savana) de Roraima. 
$1650 \mathrm{~mm}$ (Barbosa et al. 2012). As parcelas foram alocadas nas linhas de caminhamento leste-oeste de cada uma das grades, distanciadas sistematicamente $500 \mathrm{~m}$ umas das outras. A área de cada parcela amostral foi delimitada em 2 $\mathrm{m} \times 250 \mathrm{~m}$ tomando como referência o trabalho de Costa $e t$ al. (2005) para herbáceas das grades de floresta da Amazônia Central. A linha central de cada parcela acompanhou a curva de nível do terreno com o objetivo de minimizar a variabilidade topográfica e edáfica, comuns em ambientes naturais (Magnusson et al. 2005).

O inventário florístico e a coleta de material botânico (Autorizaçáo IBAMA/SISBIO n. 13616-1) foram realizados entre dezembro/2007 e agosto/2008, aproveitando os períodos de seca e chuva. Os materiais testemunhos foram incorporados aos Herbários do Instituto Nacional de Pesquisas da Amazônia (INPA) e do Museu Integrado de Roraima (MIRR). A análise do inventário florístico para todas as parcelas foi baseada na composição de espécies, riqueza $(S)$, diversidade (Índice de Shannon - H') e equabilidade de Pielou (J') (Magurran 2004). Da mesma forma, foram utilizados descritores fitossociológicos: Densidade (Den = número total de indivíduos por unidade de área), Frequência (Fre = número de parcelas em que cada espécie ocorreu) e Dominância (Dom = área da copa dos indivíduos por unidade de área), para derivar o índice de valor de importância (IVI $=\%$ Den $+\%$ Fre + \%Dom) de cada espécie independente da área amostrada.

As análises de solo foram previamente realizadas em três profundidades $(0-5 \mathrm{~cm} ; 5-10 \mathrm{~cm} ; 10-20 \mathrm{~cm})$ pelo Laboratório Temático de Solos e Plantas do INPA (Pimentel e Baccaro 2011). Em cada parcela foram utilizadas variáveis granulométricas (areia, silte e argila) e de fertilidade do solo (soma das bases), incluindo o alumínio trocável e o $\mathrm{pH}$ $\left(\mathrm{H}_{2} \mathrm{O}\right)$. Todos os valores das variáveis edáficas utilizadas neste estudo foram sumarizados para o perfil de $0-20 \mathrm{~cm}$ por média ponderada.

Cada parcela também foi caracterizada em classes de solo, drenagem, textura e de reaçáo do solo seguindo o estabelecido pelo sistema brasileiro de classificação de solos (EMBRAPA-SOLOS 2006). A indicação da classe de solo foi realizada através da sobreposição geográfica das mesmas nos mapas de solos de alta resoluçấo das duas áreas: Monte Cristo, escala no nível de detalhamento de 1:7.000 (Benedetti 2007; Benedetti et al. 2011) e Água Boa, nível de semidetalhamento de 1:20.000 (EMBRAPA-SNLCS 1990). As classes de drenagem foram verificadas ao longo da segunda etapa de observação das parcelas (período chuvoso), tomando como base a sazonalidade do lençol freático e os estudos supracitados. O uso dos mapas de solo de cada área juntamente com as observaçóes de campo serviram para complementar a verificação da presença de solos hidromórficos nas parcelas amostrais. A análise granulométrica (areia, silte e argila) serviu para a categorização das classes de textura e os valores médios de $\mathrm{pH}$ para a determinação das classes de reação do solo.

Com base no inventário florístico e na análise de solo das parcelas foi realizada uma análise de agrupamentos de dupla entrada (Two-way Cluster Analysis). O objetivo foi representar tendências de presença/ausência de grupos de espécies delimitados por grupos de parcelas, resultando em um dendrograma de dissimilaridade (hierárquico e aglomerativo). Esta análise foi realizada com base no algoritmo de agrupamento de Ward, utilizando a medida de distância Euclidiana. Este método é efetivo para análise de comunidades (McCune e Grace 2002). Os dados de densidade foram log transformados para melhorar a presunçáo de normalidade $\mathrm{e}$ equalizar a importância relativa de espécies comuns e raras.

Após este procedimento, cada grupo de parcelas foi definido como um habitat de características edáficas e estruturais semelhantes. Análise de variância (ANOVA) foi realizada para determinar diferenças entre as variáveis edáficas de cada grupo formado. Teste de Bonferroni foi utilizado para as comparaçóes múltiplas entre as médias. Para testar a homogeneidade da diversidade de espécies entre os diferentes habitats foi aplicado o Teste $t$ de Hutcheson, que compara a variância de diferentes índices tomados dois a dois. Foi utilizado o qui-quadrado para determinar diferenças no número de espécies entre os habitats.

Foram identificadas 25 espécies ( 15 gêneros) de herbáceas da família Leguminosae nas duas áreas de estudo (Tabela 1). Seis parcelas não apresentaram indivíduos. Mais de $51 \%$ do IVI foi concentrado em apenas três espécies: Chamaecrista desvauxii (24,9\%), Aeschynomene histrix (15,7\%) e Galactia jussiaeana $(10,8 \%)$; todas com alta densidade (> 1000 ind $\mathrm{ha}^{-1}$ ) e ampla distribuição. Os índices gerais de diversidade $\left(\mathrm{H}^{\prime}\right)$ e equabilidade (J') foram, respectivamente, 2,21 e 0,69.

A análise de agrupamentos identificou seis grupos de parcelas distintos por suas características edáficas e distribuição de espécies (Figura 2). Um sétimo grupo (G7) foi estabelecido pelas parcelas onde não foram observados indivíduos. De forma geral, as espécies de maior IVI formaram um grupo (ESP1) distinto daquelas com menores frequência e densidade (ESP2). Os grupos G1, G2 e G3 continham todas as parcelas do Monte Cristo e estavam relacionados à maioria das espécies de ESP1, enquanto que os demais concentravam quase todas as parcelas da região do Água Boa. A característica principal dos grupos desta última regiāo foi a presença de espécies de baixa frequência ou ausentes no Monte Cristo (e.g. Desmodium barbatum e Zornia guanipensis).

As características ambientais dos grupos de parcelas predominantes na área do Monte Cristo apontam solos bem drenados com vegetação dominada por campos sujos com ou sem mosaico de savana parque sobre Argissolo e Latossolo vermelho-amarelo (Tabela 2). Nestas parcelas, a acidez foi 


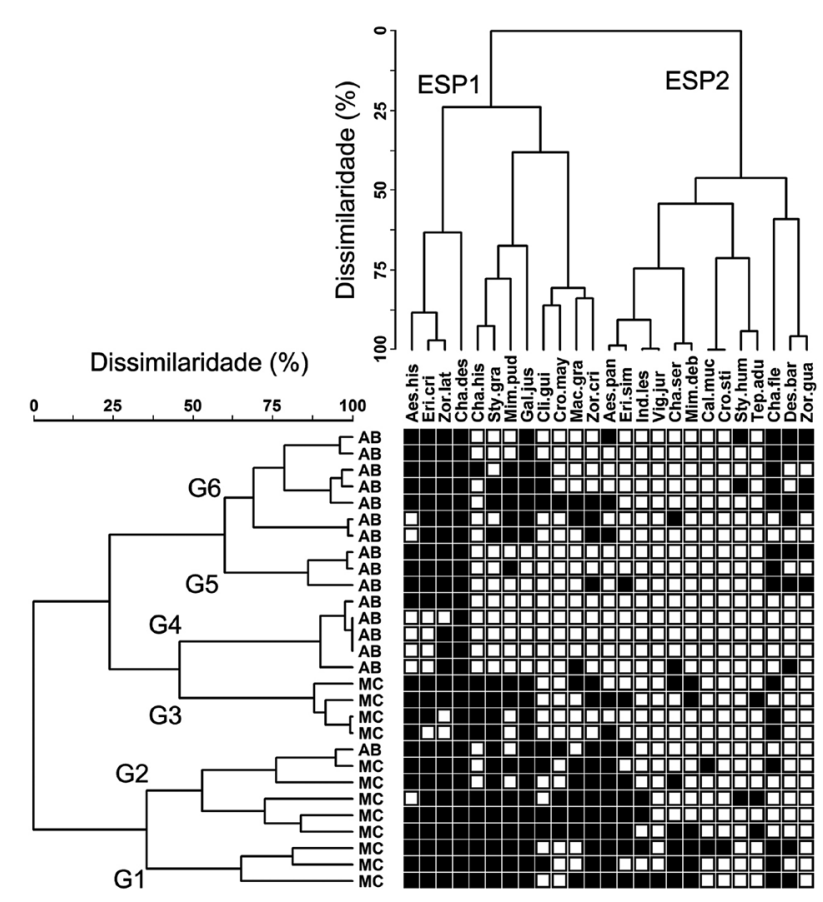

Figura 2 - Dendrograma de dissimilaridade indicando a distância florística (\%) entre as parcelas e a distribuição das espécies. Onde: $A B=$ Água Boa e MC = Monte Cristo; ESP = grupos de espécies $(1=$ espécies de maior densidade e frequência de ocorrência e 2 = espécies de menor densidade e frequencia de ocorrência) e $G=$ grupos de parcelas associados pelas variáveis edáficas. Legenda da matriz: quadrados cheios = presença de indivíduos numericamente expressos pela densidade log transformada e quadrados vazios = ausência de indivíduos. Nomenclatura das espécies está estabelecida pelas três primeiras letras do gênero e da espécie (e.g. Aes.his = Aeschynomene histrix, Zor.cri = Zornia crinitum, etc.). menor (solos moderadamente ácidos de textura média) e a soma das bases maior (ANOVA; $\mathrm{p}<0,001)$. De forma geral, os três grupos possuem maior riqueza $\left(\chi_{0,05}^{2}\right)$, embora a diversidade de G3 seja menor e semelhante ao G5, um pequeno grupo de parcelas exclusivo do Água Boa.

Em dois grupos de parcelas da região Água Boa foram observados solos mal drenados (hidromórficos) em campos limpos com vegetação higrófila. No primeiro (G4) foram observadas as menores riqueza $(S=7)$, diversidade $\left(H^{\prime}=0,44\right)$ e equabilidade $\left(J^{\prime}=0,28\right)$, enquanto no segundo (G7) foi detectada a total ausência de indivíduos herbáceos da família Leguminosae. As variáveis edáficas de destaque neste último grupo foram os menores valores absolutos para soma de bases e pH (alta acidez), e a maior concentração de alumínio trocável (ANOVA; $\mathrm{p}<0,001)$.

O número de espécies de $\mathrm{G} 5(\mathrm{~S}=10)$ foi considerado intermediário entre os grupos de maior (G1, G2, G3 e G6) e menor (G4) riqueza, pois não diferiu entre ambos (Tabela 2). Contudo, sua diversidade foi baixa em função da alta concentração de indivíduos da espécie $C$. desvauxii (IVI = $73,2 \%$ ). O grupo G5 possui baixa concentração de argila e alta de areia, da mesma forma como em G4, mas ambos se distinguem pelo sistema de drenagem. O grupo G6, também situado no Água Boa, é totalmente compatível com os grupos mais ricos e diversos do Monte Cristo, embora seja menos fértil e de maior acidez.

Os resultados desse estudo indicam maior riqueza de plantas herbáceas da família Leguminosae em relação às 15 espécies verificadas na savana de Alter do Chão (PA) por Magnusson et al. (2008). Contudo, os resultados dessa investigação são plenamente compatíveis com levantamentos

Tabela 1 - Composição, riqueza, diversidade e índice de valor de importância de herbáceas da família Leguminosae inventariadas em 34 parcelas permanentes situadas em duas áreas da savana de Roraima, norte da Amazônia Brasileira.

\begin{tabular}{|c|c|c|c|c|c|c|c|}
\hline \multirow{2}{*}{ Espécie } & \multicolumn{2}{|c|}{ Densidade } & \multicolumn{2}{|c|}{ Dominância } & \multicolumn{2}{|c|}{ Frequência } & \multirow{2}{*}{ IVI (\%) } \\
\hline & ind ha-1 & $\%$ & $\mathrm{~m}^{2} \mathrm{ha}^{-1}$ & $\%$ & $\mathrm{n}$ & $\%$ & \\
\hline Chamaecrista desvauxii (Collad.) Killip & 4173,7 & 37,5 & 47,0 & 27,0 & 28 & 10,1 & 24,9 \\
\hline Aeschynomene histrix Poir. & 1123,8 & 10,1 & 51,1 & 29,4 & 21 & 7,6 & 15,7 \\
\hline Galactia jussiaeana Kunth & 1122,1 & 10,1 & 26,6 & 15,3 & 20 & 7,2 & 10,8 \\
\hline Eriosema crinitum (Kunth) G. Don & 1118,1 & 10,0 & 8,3 & 4,8 & 23 & 8,3 & 7,7 \\
\hline Zornia latifolia Sm. & 808,8 & 7,3 & 2,9 & 1,7 & 25 & 9,0 & 6,0 \\
\hline Chamaecrista hispidula (Vahl) H.S. Irwin \& Barneby & 539,0 & 4,8 & 10,4 & 6,0 & 11 & 4,0 & 4,9 \\
\hline Mimosa pudica L. & 249,3 & 2,2 & 6,7 & 3,8 & 15 & 5,4 & 3,8 \\
\hline Zornia crinita (Mohlenbr.) Vanni & 515,4 & 4,6 & 1,1 & 0,6 & 15 & 5,4 & 3,5 \\
\hline Stylosanthes gracilis Kunth & 319,6 & 2,9 & 1,3 & 0,8 & 16 & 5,8 & 3,1 \\
\hline Eriosema simplicifolium (Kunth) G. Don & 241,5 & 2,2 & 2,6 & 1,5 & 9 & 3,2 & 2,3 \\
\hline Chamaecrista flexuosa (L.) Greene & 64,5 & 0,6 & 1,4 & 0,8 & 15 & 5,4 & 2,3 \\
\hline Aeschynomene paniculata Vogel & 110,6 & 1,0 & 1,1 & 0,6 & 14 & 5,0 & 2,2 \\
\hline Indigofera lespedezioides Kunth & 136,0 & 1,2 & 4,6 & 2,7 & 4 & 1,4 & 1,8 \\
\hline
\end{tabular}


Tabela 1 - Continuação

\begin{tabular}{lccccccc}
\hline \multirow{2}{*}{ Espécie } & \multicolumn{2}{c}{ Densidade } & \multicolumn{3}{c}{ Dominância } & \multicolumn{2}{c}{ Frequência } \\
\cline { 2 - 5 } & ind ha-1 & $\%$ & $\mathrm{~m}^{2}$ ha $^{-1}$ & $\%$ & $\mathrm{n}$ & $\%$ & IVI (\%) \\
\hline Chamaecrista serpens (L.) Greene & 102,6 & 0,9 & 2,5 & 1,4 & 8 & 2,9 & 1,7 \\
Desmodium barbatum (L.) Benth. & 107,5 & 1,0 & 1,5 & 0,8 & 9 & 3,2 & 1,7 \\
Clitoria guianensis (Aubl.) Benth. & 157,7 & 1,4 & 0,5 & 0,3 & 8 & 2,9 & 1,5 \\
Macroptilium gracile (Benth.) Urb. & 42,8 & 0,4 & 0,2 & 0,1 & 10 & 3,6 & 1,4 \\
Zornia cf. guanipensis Pittier & 50,2 & 0,5 & 1,6 & 0,9 & 6 & 2,2 & 1,2 \\
Mimosa debilis Willd. & 75,9 & 0,7 & 0,4 & 0,2 & 6 & 2,2 & 1,0 \\
Crotalaria maypurensis Kunth & 25,6 & 0,2 & 0,7 & 0,4 & 5 & 1,8 & 0,8 \\
Tephrosia adunca Benth. & 33,4 & 0,3 & 0,4 & 0,2 & 3 & 1,1 & 0,5 \\
Calopogonium mucunoides Desv. & 9,2 & 0,1 & 0,9 & 0,5 & 2 & 0,7 & 0,4 \\
Stylosanthes humilis Kunth & 7,9 & 0,1 & 0,1 & 0,1 & 3 & 1,1 & 0,4 \\
Vigna juruana (Harms) Verdc. & 4,1 & 0,0 & 0,0 & 0,0 & 1 & 0,4 & 0,1 \\
Crotalaria stipularia Desv. & 1,2 & 0,0 & 0,0 & 0,0 & 1 & 0,4 & 0,1 \\
Total & 11140,4 & 100 & 173,8 & 100 & 34 & 100 & 100 \\
\hline
\end{tabular}

Tabela 2 - Características ambientais, edáficas e fitossociológicas dos grupos de parcelas formados pela análise de agrupamentos (Two-way Cluster Analysis). Onde: $\mathrm{SB}=$ soma das bases $(\mathrm{Ca}+\mathrm{Mg}+\mathrm{K})$; letras minúsculas indicam diferenças entre as médias dos atributos do solo (ANOVA; Bonferroni; $\alpha=0,05)$; letras maiúsculas indicam diferenças entre os valores de riqueza $\left(\chi_{0,05}^{2}\right)$ e índices de diversidade (Teste $t_{0,05}$ de Hutcheson).

\begin{tabular}{|c|c|c|c|c|c|c|c|}
\hline \multirow{2}{*}{ Atributos do Solo } & \multicolumn{7}{|c|}{ Grupos de Parcelas (número de parcelas) } \\
\hline & G1 (3) & G2 (6) & G3 (4) & G4 (5) & G5 (3) & G6 (7) & G7 (6) \\
\hline $\operatorname{Argila~}\left(\mathrm{g} \mathrm{kg}^{-1}\right)$ & $154,2 \pm 48,2$ bc & $149,0 \pm 39,9 b$ & $225,9 \pm 73,9 c$ & $109,8 \pm 59,9 a$ & $83,3 \pm 9,5 a$ & $172,1 \pm 34,8 b c$ & $150,0 \pm 95,4 b$ \\
\hline Silte $\left(\mathrm{g} \mathrm{kg}^{-1}\right)$ & $79,2 \pm 26,2 b$ & $59,7 \pm 23,7 a b$ & $84,0 \pm 20,9 b$ & $42,6 \pm 11,0 \mathrm{a}$ & $43,6 \pm 10,0 a$ & $45,2 \pm 14,6 \mathrm{a}$ & $90,4 \pm 54,2 b$ \\
\hline Areia $\left(\mathrm{g} \mathrm{kg}^{-1}\right)$ & $766,7 \pm 69,8$ a & $791,4 \pm 54,7 b c$ & $690,1 \pm 71,5 \mathrm{a}$ & $847,7 \pm 63,8 b c$ & $873,1 \pm 19,0 \mathrm{c}$ & $782,7 \pm 42,7 \mathrm{~b}$ & $759,6 \pm 113,9 a$ \\
\hline $\mathrm{pH}\left(\mathrm{H}_{2} \mathrm{O}\right)$ & $5,63 \pm 0,24 c$ & $5,49 \pm 0,15 c$ & $5,65 \pm 0,16 c$ & $5,19 \pm 0,35 a b$ & $5,28 \pm 0,25 b c$ & $5,16 \pm 0,25 a b$ & $4,91 \pm 0,42 a$ \\
\hline $\mathrm{SB}\left(\mathrm{cmolc} \mathrm{kg}^{-1}\right)$ & $0,527 \pm 0,306 \mathrm{c}$ & $0,353 \pm 0,124 \mathrm{c}$ & $0,326 \pm 0,129 c$ & $0,170 \pm 0,047 b$ & $0,158 \pm 0,056 a b$ & $0,230 \pm 0,050 b$ & $0,105 \pm 0,021 \mathrm{a}$ \\
\hline $\mathrm{Al}\left(\mathrm{cmolc} \mathrm{kg}^{-1}\right)$ & $0,314 \pm 0,041 \mathrm{a}$ & $0,300 \pm 0,085 a$ & $0,375 \pm 0,81 \mathrm{a}$ & $0,367 \pm 0,184 a$ & $0,284 \pm 0,042 \mathrm{a}$ & $0,411 \pm 0,057 \mathrm{a}$ & $0,607 \pm 0,271 b$ \\
\hline $\begin{array}{l}\text { Classe de Dre- } \\
\text { nagem }\end{array}$ & Bem drenado & Bem drenado & Bem drenado & $\begin{array}{c}\text { Imperfeitamente } \\
\text { drenado } \\
\text { (1-2 meses) }\end{array}$ & Bem drenado & Bem drenado & $\begin{array}{l}\text { Mal drenado } \\
\text { (2-4 meses) }\end{array}$ \\
\hline Grupo Textural & Média & Média & Média & Arenosa & Arenosa & Média & Média \\
\hline Classe de Reação & $\begin{array}{l}\text { Moderadamente } \\
\text { Ácido }\end{array}$ & $\begin{array}{l}\text { Moderadamente } \\
\text { Ácido }\end{array}$ & $\begin{array}{l}\text { Moderadamente } \\
\text { Ácido }\end{array}$ & $\begin{array}{l}\text { Fortemente } \\
\text { Ácido }\end{array}$ & Fortemente Ácido & Fortemente Ácido & $\begin{array}{l}\text { Fortemente } \\
\text { Ácido }\end{array}$ \\
\hline $\begin{array}{l}\text { Classe de Solo } \\
\text { Predominante }\end{array}$ & $\begin{array}{l}\text { Latossolo } \\
\text { vermelho-amarelo }\end{array}$ & Argissolo & $\begin{array}{c}\text { Latossolo amarelo } \\
\text { / Argissolo / } \\
\text { Plintossolo pétrico }\end{array}$ & $\begin{array}{c}\text { Contato } \\
\text { Latossolo } \\
\text { amarelo/Gleissolo }\end{array}$ & $\begin{array}{l}\text { Latossolo } \\
\text { amarelo }\end{array}$ & $\begin{array}{l}\text { Plintossolo } \\
\text { Háplico / } \\
\text { Latossolo } \\
\text { amarelo }\end{array}$ & $\begin{array}{l}\text { Hidromórfico } \\
\text { (Gleissolo) }\end{array}$ \\
\hline Vegetação & $\begin{array}{l}\text { Mosaico campo / } \\
\text { parque }\end{array}$ & $\begin{array}{l}\text { Mosaico campo / } \\
\text { parque }\end{array}$ & $\begin{array}{l}\text { Mosaico campo } \\
\text { sujo/parque }\end{array}$ & $\begin{array}{l}\text { Mosaico campo } \\
\text { limpo/vegetação } \\
\text { higrófila }\end{array}$ & Campo Limpo & $\begin{array}{l}\text { Mosaico campo } \\
\text { limpo/campo } \\
\text { sujo }\end{array}$ & $\begin{array}{c}\text { Campo limpo } \\
\text { de vegetação } \\
\text { higrófila }\end{array}$ \\
\hline \multirow{2}{*}{$\begin{array}{l}\text { Principais } \\
\text { Espécies } \\
\text { (IVl; \%) }\end{array}$} & $\begin{array}{l}\text { C. hispidula } \\
(23,8 \%)\end{array}$ & $\begin{array}{c}\text { A. histrix } \\
(27,6 \%)\end{array}$ & $\begin{array}{l}\text { C. desvauxii } \\
(49,2 \%)\end{array}$ & $\begin{array}{l}\text { C. desvauxii } \\
(84,2 \%)\end{array}$ & $\begin{array}{l}\text { C. desvauxii } \\
(73,2 \%)\end{array}$ & $\begin{array}{l}\text { C. desvauxii } \\
(25,1 \%)\end{array}$ & - \\
\hline & $\begin{array}{l}\text { E. simplicifolium } \\
\qquad(12,2 \%)\end{array}$ & $\begin{array}{l}\text { C. desvauxii } \\
(19,9 \%)\end{array}$ & $\begin{array}{c}\text { G. jussiaeana } \\
(36,2 \%)\end{array}$ & $\begin{array}{l}\text { D. barbatum } \\
(5,6 \%)\end{array}$ & $\begin{array}{c}\text { A. histrix } \\
(12,5 \%)\end{array}$ & $\begin{array}{l}\text { Z. Iatifolia } \\
(20,6 \%)\end{array}$ & - \\
\hline Riqueza (S) & $21 \mathrm{C}$ & $21 \mathrm{C}$ & $16 \mathrm{C}$ & $7 \mathrm{~B}$ & $10 B C$ & $18 \mathrm{C}$ & $0 \mathrm{~A}$ \\
\hline Diversidade (H') & $2,57 \mathrm{C}$ & $2,20 \mathrm{C}$ & $1,27 \mathrm{~B}$ & $0,44 \mathrm{~A}$ & $0,94 \mathrm{AB}$ & $1,93 \mathrm{C}$ & - \\
\hline Equabilidade (J') & 0,84 & 0,72 & 0,46 & 0,28 & 0,41 & 0,67 & - \\
\hline
\end{tabular}


florísticos realizados anteriormente na savana de Roraima, como os de Miranda e Absy (2000) e Flores e Rodrigues (2010), que observaram, respectivamente, 25 e 21 espécies deste grupo de plantas.

Nossas análises fornecem pistas importantes para delimitação dos padrôes de ocorrência, riqueza e diversidade do grupo modelo em função de variáveis edáficas e outras características ambientais que delimitam a heterogeneidade de habitats na savana de Roraima. Por exemplo, áreas com deficiência de drenagem, baixa fertilidade natural e alta saturação de $\mathrm{Al}$ trocável, indicaram tendências de menor riqueza e diversidade de espécies, ou total ausência de indivíduos. Dois grupos de parcelas com estas características foram encontradas na região Água Boa, estabelecidas em zonas de depressão com campos naturais holocênicos desenvolvidos em solos hidromórficos com baixos teores de bases trocáveis e alta saturação por Al (EMBRAPA-SNLCS 1990). Ao contrário, a maioria das parcelas do Monte Cristo se encontrava em áreas de savana bem drenada, mais arborizada e solos com maior soma de bases e menor acidez; características induzidas pela gênese dos solos daquela região que é dominada por mosaicos de sedimentos Pliopleistocênicos a rochas vulcânicas básicas (Benedetti et al. 2011). Nestas últimas condições edáficas e ambientais foi observado tendência de maior riqueza e diversidade do grupo modelo.

Neste estudo de caso, a drenagem foi um parâmetro importante no estabelecimento do grupo modelo, visto que mesmo com problemas de acidez e fertilidade, um dos grupos da regiấo Água Boa (G6) figurava entre os mais ricos e diversos. Por outro lado, alumínio trocável e $\mathrm{pH}$ são variáveis que influenciam na ocorrência e distribuição de espécies arbóreas na savana de Roraima (Miranda et al. 2002). Portanto, em associação com a drenagem, estes atributos demonstram ser importantes preditores para diferentes grupos de plantas em áreas abertas da Amazônia. Curiosamente, embora o conteúdo de argila tenha apresentado diferenças entre os grupos de parcelas, esta variável física foi pouco efetiva como preditora, ao contrário do observado em outros estudos na Amazônia (e.g. Kinupp e Magnusson 2005).

As duas áreas amostrais apresentaram heterogeneidade ambiental específica e com grupos de parcelas exclusivos devido a diferentes formaçôes pedológicas. Desta forma, há de se supor processos de relacionamentos distintos entre variáveis edáficas para cada sítio amostral. Neste caso, os padrôes de distribuição de cada área individual (microescala) podem dificultar o entendimento dos reais fatores que estruturam a comunidade no nível da macroescala (Zuquim et al. 2012). Assim sendo, seriam necessários estudos em um maior número de localidades para suprimir este problema e revelar padrôes gerais de distribuiçáo de comunidades de plantas herbáceas em áreas de savana na Amazônia.
Conclui-se que solos pobres e sazonalmente alagados reduzem as chances de ocorrência e afetam negativamente a riqueza/diversidade de leguminosas herbáceas em áreas de savana em Roraima.

\section{AGRADECIMENTOS}

J. Lima e C. A. Cid Ferreira cederam espaço e colaboraram com as primeiras identificaçôes taxonômicas realizadas no Herbário INPA. C. O. Cavalcante recebeu bolsa da Coordenaçáo de Aperfeiçoamento de Pessoal de Nível Superior (CAPES) através do Programa de Pós-graduação em Recursos Naturais da Universidade Federal de Roraima (PRONAT/UFRR). R. I. Barbosa recebeu bolsa produtividade do Conselho Nacional de Desenvolvimento Científico e Tecnológico (CNPq).

\section{BIBLIOGRAFIA CITADA}

Barbosa, R.I.; Campos, C. 2011. Detection and geographical distribution of clearing areas in the savannas ('lavrado') of Roraima using Google Earth web tool. Journal of Geography and Regional Planning, 4: 122-136.

Barbosa, R.I.; Nascimento, S.P.; Amorim, P.A.F.; Silva, R.F. 2005. Notas sobre a composição arbóreo-arbustiva de uma fisionomia das savanas de Roraima, Amazônia Brasileira. Acta Botanica Brasilica, 19: 323-329.

Barbosa, R.I.; Santos, J.R.S.; Cunha, M.S.; Pimentel, T.P.; Fearnside, P.M. 2012. Root biomass, root: shoot ratio and belowground carbon stocks in the open savannahs of Roraima, Brazilian Amazonia. Australian Journal of Botany, 60: 405-416.

Benedetti, U.G. 2007. Estudo detalhado dos solos do Campus do Cauamé da UFRR, Boa Vista, Roraima. Universidade Federal de Roraima, Boa Vista. 105 pp.

Benedetti, U.G.; Vale Jr, J.F. ; Schaefer, C.E.G.R.; Melo, V.F.; Uchôa, S.C.P. 2011. Gênese, química e mineralogia de solos derivados de sedimentos pliopleistocênicos e de rochas vulcânicas básicas em Roraima, Norte Amazônico. Revista Brasileira de Ciência do Solo, 35: 299-312.

Costa, F.R.C. 2006. Mesoscale gradients of herb richness and abundance in Central Amazonia. Biotropica, 38: 711-717.

Costa, F.R.C.; Magnusson, W.E.; Luizão, R.C. 2005. Mesoscale distribution patterns of Amazonian understorey herbs in relation to topography, soil and watersheds. Journal of Ecology, 93: 863-878.

EMBRAPA-SNLCS. 1990. Levantamento semidetalhado dos solos $e$ aptidão agrícola das terras do Campo Experimental Água Boa do CPAF-RR, Estado de Roraima. Vol. sn. Embrapa, Serviço Nacional de Levantamento e Conservaçáo de Solos, Rio de Janeiro, 1990, 127p.

EMBRAPA-SOLOS. 2006. Sistema Brasileiro de Classificação dos Solos. Embrapa Solos, Rio de Janeiro, 2006, 306p.

Flores, A.S.; Rodrigues, R.S. 2010. Diversidade de Leguminosae em uma área de savana do estado de Roraima, Brasil. Acta Botanica Brasilica, 24: 175-183. 
Kinupp, V.F.; Magnusson, W.E. 2005. Spatial patterns in the understorey shrub genus Psychotria in central Amazonia: effects of distance and topography. Journal of Tropical Ecology, 21:363-374.

Lewis, G.P.; Schrire, B.; Mackinder, B.; Lock, M. 2005. Legumes of the World. Royal Botanic Gardens, Kew, 2005, 592p.

Magnusson, W.E.; Lima, A.P.; Albernaz, A.L.K.M.; Sanaiotti, T.M.; Guillaumet, J.-L. 2008. Composição florística e cobertura vegetal das savanas na região de Alter do Chão, Santarém - PA. Revista Brasileira de Botânica, 31: 165-177.

Magnusson, W.E.; Lima, A.P.; Luizão, R.; Luizão, F.; Costa, F.R.C.; Castilho, C.V.; Kinupp, V.F. 2005. RAPELD: A modification of the Gentry Method for biodiversity surveys in long-term ecological research sites. Biota Neotropica, 5: 19-24.

Magurran, A.E. 2004. Measuring biological diversity. Blackwell, Malden, MA, 2004, 215p.

McCune, B.; Grace, J.B. 2002. Analysis of ecological communities. MjM Software Design, USA, 2002, 300p.

Miranda, I.S.; Absy, M.L. 2000. Fisionomia das savanas de Roraima, Brasil. Acta Amazonica, 30: 423-440.

Miranda, I.S.; Absy, M.L.; Rebêlo, G.H. 2002. Community structure of woody plants of Roraima savannahs, Brazil. Plant Ecology, 164: 109-123.

Miranda, I.S.; Almeida, S.S.; Dantas, P.J. 2006. Florística e estrutura de comunidades arbóreas em cerrados de Rondônia, Brasil. Acta Amazonica, 36: 419-430.

Pimentel, T.P.; Baccaro, F. 2011. Coletas e análises físico-químicas do solo em parcelas permanentes em ecossistemas de Savana. Campus Experimental Cauamé / Monte Cristo - UFRR (http://ppbio.inpa.gov.br/knb/metacat/menger.170.1/ppbio) e Campo Experimental Água Boa - Embrapa Roraima (http:// ppbio.inpa.gov.br/knb/metacat/menger.149.4/ppbio). Acesso em 04/05/2011.
Ratter, J.A.; Bridgewater, S.; Ribeiro, J.F. 2003. Analysis of the floristic composition of the Brazilian Cerrado vegetation III: comparison of the woody vegetation of 376 areas. Edinburgh Journal of Botany, 60: 57-109.

Sanaiotti, T.M.; Martinelli, L.A.; Victoria, R.L.; Trumbore, S.E.; Camargo, P.B. 2002. Past vegetation changes in Amazon savannas determined using carbon isotopes of soil organic matter. Biotropica, 34: 2-16.

Santos, C.P.F.; Valles, G.F.; Sestini, M.F.; Hoffman, P.; Dousseau, S.L.; Homem de Mello, A.J. 2007. Mapeamento dos remanescentes e ocupação antrópica no Bioma Amazônia. (http://marte.dpi. inpe.br/rep/dpi.inpe.br/sbsr@80/2006/11.18.01.25?mirror=dpi. inpe.br/banon/2003/12.10.19.30.54\&metadatarepository=dpi. inpe.br/sbsr@80/2006/11.18.01.25.31).Acesso em 08/04/2009

Tuomisto, H.; Poulsen, A.D.; Ruokolainen, K.; Moran, R.C.; Quintana, C.; Celi, J.; Cañas, G. 2003. Linking floristic patterns with soil heterogeneity and satellite imagery in Ecuadorian Amazonia. Ecological Application, 13: 352-371.

Zuquim, G.; Tuomisto, H.; Costa, F.R.C.; Prado, J.; Magnusson, W.E.; Pimentel, T.; Braga-Neto, R.; Figueiredo, F.O.G. 2012. Broad scale distribution of Ferns and Lycophytes along environmental gradients in Central and Northern Amazonia, Brazil. Biotropica, 44: 752-762.

Recebido em 04/03/2013

Aceito em 27/08/2013 
